\title{
Demand Management
}

\author{
Chris K. Anderson
}

Pricing is one of the key drivers of firm profits. Revenue management (RM) is predicated on variable and responsive pricing actions in an effort to optimally match supply with demand. Historically, the matching of supply and demand via RM has been a process of rejecting lower valued demand or reserving capacity for higher yielding demand in the face of excess demand. More recently, RM has been taking a more active pricing role as supply has exceeded demand. The following is a commentary on the four chapters comprising Part VI, with some extensions and discussion of the future role of integrated pricing and marketing within an RM framework-more succinctly referred to as demand management (Anderson \& Carroll, 2007).

In Chapter 35, Cross, Higbie, and Cross provided an excellent synopsis of RM and its evolution from the airline industry through its early adoption by Marriott into today's look at RM within hospitality. Marriott's assessment of RM adding $\$ 200$ million to the top line (Mariott \& Cross, 2000) is consistent with American Airline's early assessment that RM was adding \$500 million to its top line (Smith, Leimkuhler, \& Darrow, 1992). As Cross et al. noted in Chapter 35, early RM dealt with the protection of inventory for higher yielding late-arriving customers.

RM has often been motivated by a simple illustration of variable versus fixed pricing; such an example was provided in Chapter 35. Exhibit 38.1a is similar to Cross et al.'s Exhibit 35.1 in Chapter 35, with the areas outlined by the rectangles representing firm revenues and the areas to the right and above of the rectangles representing forgone revenue. As illustrated by Sheryl Kimes (in Chapter 34), firms use a variety of fences or restrictions to enable the service provider to sell $Q_{1}$ rooms at price $P_{1}$ while simultaneously selling $Q_{0}-Q_{1}$ rooms at price $P_{0}$. The firm needs these fences to prevent the $Q_{1}$ customers from buying down and paying the lower $P_{0}$. More often than not, these fences fail to fully restrict customers from paying less than their maximum willingness to pay with some of the $Q_{1}$ customers paying $\mathrm{P}_{0}$ instead of $\mathrm{P}_{1}$ Exhibit $38.1 \mathrm{~b}$ casts la (a traditional microeconomic take on variable pricing) into a marketing view of variable pricing. Think of Exhibit 38.1a as price discrimination and Exhibit $38.1 \mathrm{~b}$ as market segmentation-where each of the dashed lines presents a segment of the aggregated (total) market represented by the solid line. The service provider is then setting a revenue 
maximizing price in each distinct market segment versus trying to discriminate across nonsegmented consumers. The point is that unless a firm can effectively segment consumers (whether by fences or other mechanisms), they should not be trying to implement variable pricing. As indicated by Kimes (in Chapter 34), in addition to revenue dilution, customers may perceive the resulting price discrimination as unfair.

\section{Exhibit 38.1 Variable Pricing}

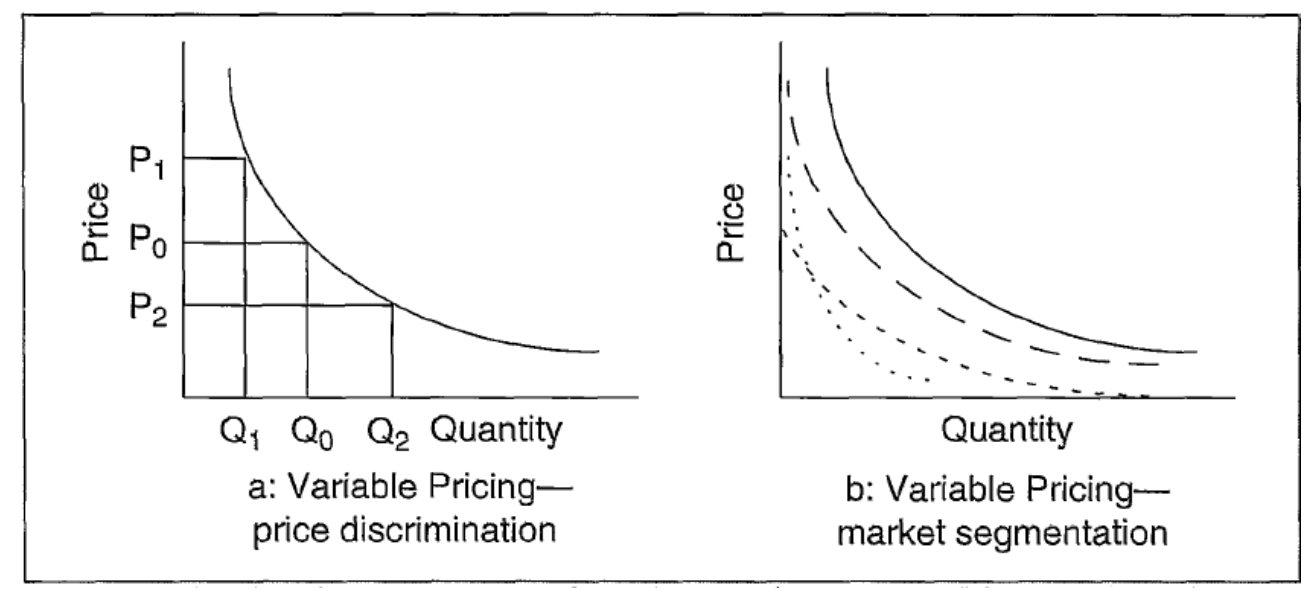

Dynamic pricing in its purest form is distinct from variable pricing. Using the illustration in

Exhibit $38.1 \mathrm{~b}$ as motivation, variable pricing is the setting of multiple price points into distinct market segments-each potentially being offered simultaneously. Dynamic pricing is the changing of one or more of these price points over time in response to demand uncertainty (usually decreasing price to stimulate demand). When contemplating a price change, firms need to first assess the required demand response to make the price change contribution positive. As an example, consider Exhibit 38.2, where a firm is contemplating decreasing prices from $P_{1}$ to $P_{2}$. The firm would have sold $Q_{1}$ at $P_{1}$ by lowering prices to $P_{2}$ They forgo the contribution outlined in area $A,\left(P_{1}-P_{2}\right) * Q_{1}$ while they receive new contribution defined by $\mathrm{B},\left(Q_{2}-Q_{1}\right) J^{*}\left(P_{2}-V C\right)$. The price change will be contribution positive as long as $\mathrm{B}>$ $A$. The price change breaks even if $A=B$; we can express this break-even $\frac{Q_{1}-Q_{2}}{Q_{1}}=\frac{P_{1}-P_{2}}{P_{2}-V C}$ or $\%$ change in demand $\frac{Q_{1}-Q_{2}}{Q_{1}}=\frac{-\Delta P}{\Delta P+C M}$ where $C M$ is the firm's original contribution margin $\left(\mathrm{P}_{1}-\mathrm{VC}\right)$ and $\triangle P$ is $P_{1}-P_{2}$.

We can use these break-even expressions to understand contribution positive price changesessentially if you don't think you can achieve the required break-even demand increase then don't decrease prices (works the same if considering a price increase). The fundamental issue firms fail to consider when making price changes is that all consumers pay (or don't pay) the new price-even those 
who would have paid more had prices not been decreased. We can generalize price changes to a few basic concepts:

- Decrease prices (either proactive or reactive-following a competitors price reduction) in price sensitive segments (often called elastic) - those segments where $\frac{Q_{1}-Q_{2}}{Q_{1}}>\frac{P_{1}-P_{2}}{P_{1}}$, conversely

- Raise prices (or follow a competitor's price increase) in nonprice sensitive segments (inelastic) i.e., $\frac{Q_{1}-Q_{2}}{Q_{1}}<\frac{P_{1}-P_{2}}{P_{1}}$.

\section{Exhibit 38.2 Break-Even Price Changes}

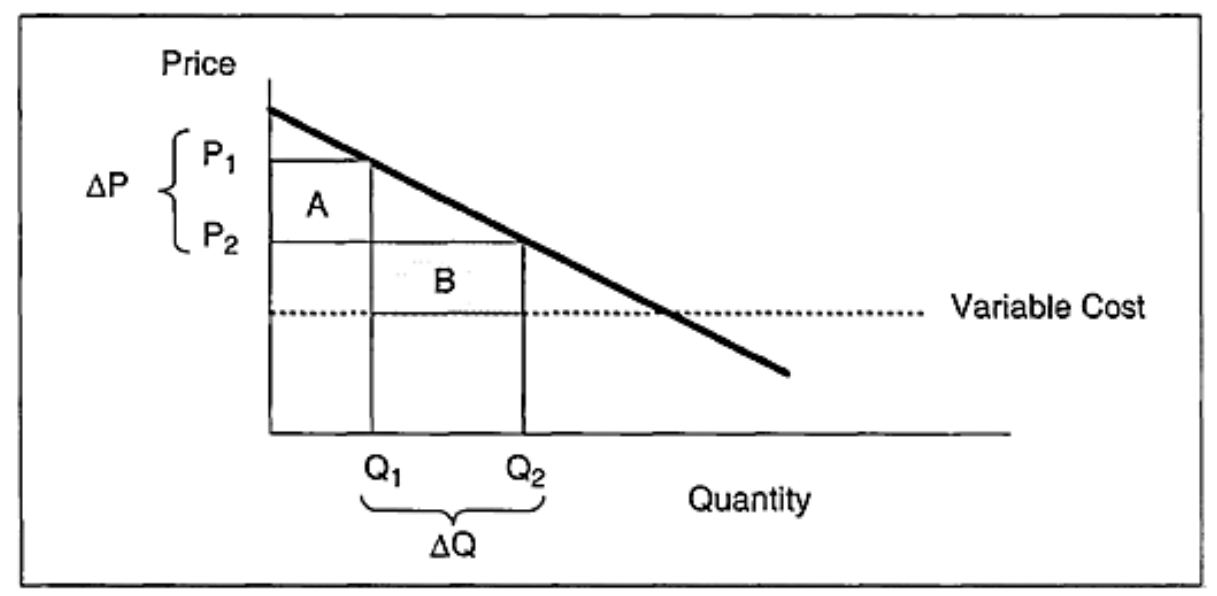

They key term here is segments, indicating firms should not universally price dynamically but rather target price changes at specific market segments, as only targeted price changes will generate enough incremental demand to compensate for rate dilution.

Firms need to separate how they approach variable versus dynamic pricing. In Chapter 34, Kimes presented several key insights around variable pricing-both how these prices should be set and who should get them. Restrictions and rate fences can be effective at setting variable prices but become less effective at controlling availability or segmenting when dynamically pricing as many of the effective rate fences are linked to time. Over time, price sensitive customers have become accustomed to shopping early for the best prices, indicating that as firms adjust prices (often decreasing them) in response to demand uncertainty they are pricing into inelastic demand with price reductions becoming contribution negative.

As firms approach the arrival date and are looking for methods to reach price sensitive customers, they need to think more like a marketer in an effort to make sure their price changes are 
targeted. Today's online world has facilitated price shopping (both across firms and within a firm across channels) and moved firms to price parity as a result of the ease within firm (across channel) price comparisons. The ease of price comparisons requires firms to offer discounts in a private fashion. Private discounts or opaque discounts allow discounts to be presented to price sensitive (elasticcontribution positive from price reductions) customers while maintaining higher prices on regular posted price channels. Private discounts can be facilitated by opaque online travel agents like Priceline's "Name Your Own Price" channel (see Anderson [2009] for details) or on Hotwire (see Anderson and Xie [2009] for details). Both Priceline and Hotwire hide the name of the property until after the purchase, allowing the service provider to reach price sensitive (non-brand loyal consumers) while simultaneously reaching brand loyal customers at higher prices. Bundling is another method of offering private discounts whereby the service is bundled with other services (air and hotel combined) with the customer paying a (reduced) package price. Finally, today's online advertising world offers numerous ways to market to customers at a very granular level-whether via your customer relationship management (CRM) system with e-mail offers or through an online search engine (e.g., Google, Yahoo, or Bing) where you can pay for very specific exposure of your ads with links to special reduced prices. Dynamic pricing needs considerable attention in order to avoid the commoditization of hotel rooms similar to how it has commoditized an airline seat with customers switching airlines for only a few dollars.

While strategic pricing can be thought of as setting the correct set of variable prices, it also entails pricing of ancillary services as well as setting hurdles for negotiated rates-rates that are often set months or years prior to arrival. In Chapter 35, Cross et al. indicated that as much as $60 \%$ of revenues for many full service hotels are attributed to groups, yet group pricing has received very little research attention. I refer to group pricing as pricing of negotiated blocks of rooms far in advance of arrival-these blocks may be for a conference, a function, crew, or corporate rates. Historically, group pricing has involved some estimate of displaced transient room nights with the group required to bring in at least as much profit as the displaced transients (see Schwartz and Cohen [2003] for a summary). In Chapter 36, Choi presented a more detailed look at determining acceptable group prices. Choi outlined that displaced transient rooms should be calculated rate class by rate class, assuming the group first displaces the lowest rate class and then displaces rooms from higher rate classes in increasing yield. The total displaced transient revenues can then be compared to the estimated group rooms that will be sold (probably less than the block size) and the corresponding rate. The inclusion of profit from group ancillary sales further adds to the profits from the group and helps to reduce the required group rate. 
Choi also demonstrated the necessity to focus on contribution, not revenues, when making group accept or reject decisions. When pricing groups, firms often forget to consider the fact that the group often adds incremental demand to the property (demand that otherwise would not exist). The acceptance of the group means the hotel is effectively revenue managing a smaller hotel. As a result, the hotel should consider raising its transient rates versus simply closing out discounted rates as is assumed by Choi in Chapter 36 (as well as by Schwartz and Cohen [2003]). Anderson, Carroll, and Li (2007) provided several illustrative examples of the impact accepting a group can have on the ability to price transients; the following is one such example.

Consider a property that has forecasted occupancy of less than $100 \%$. With a capacity $(k)$ of 1,600 rooms, the hotel charges a single rate of $\$ 125\left(P_{0}\right)$ and expects to sell 1,500 rooms $\left(Q_{0}\right)$, achieving an expected occupancy rate of $94 \%$, producing a profit of $\$ 112,500$ under the single-rate policy, assuming variable costs of $\$ 50$. We set the price of $\$ 125$, assuming that demand follows a simple linear demand curve $P=200-0.05 Q$ or $Q=4000-20 P$. Suppose the hotel receives a group booking request of 400 rooms. Under what conditions should the hotel accept the booking?

Assume that the group rate is $P_{g^{*}}$ If the hotel accepts the group booking, its profit consist of two components: selling 400 rooms at group rate $P_{g}$, contributing $400\left(\mathrm{P}_{\mathrm{g}}-50\right)$ to the profit, and selling the remaining 1,200 rooms to the transient customers at the new market clearing price of $\$ 140$, earning a profit of $\$ 108,000$. Therefore, the group will be accepted if and only if $400\left\{P_{g}-50\right)+108,000 \geq 112,500$ $\Leftrightarrow 400\left(P_{g}-50\right)+108,000 \geq 112,500 \Leftrightarrow P_{g}>\$ 61.25$

which implies that the minimum acceptable group rate $\left\{P_{g}{ }^{m i n}\right)$ is $\$ 61.25$ for a confirmed group of 400 . An interesting insight here is that the gain from the price increase will not be sufficient to offset the losses due to displacement of customers. This means that the hotel must rely on the profit from the group to balance the net decrease in the profit level from the transient market. The traditional approach, see Schwartz and Cohen (2003), works as follows: (1) the cost of the displacement of 300 (1500-1200) transient customers at the price $\$ 125$ is given by $300 \times(125-50)=\$ 22,500$ and (2) the profit from the group is $400\left(P_{g}-50\right)$. It means that the group booking will be accepted if and only if $400\left(P_{g}-50\right)>$ 22,500 , i.e., $P_{g} \geq \$ 106.25$ ! It is clear that the traditional model overestimates the opportunity cost because of its inability to take into account the impact of sizable group bookings on the price in the transient market $(\$ 22,500$ versus $\$ 4,500)$, as accepting the group allows the hotel to price its transients higher (at $\$ 140$ versus $\$ 125$ ). The managerial implications of this overestimation are twofold: (1) it gives 
the sales and marketing department very little space to negotiate the group rate and (2) there are many missed opportunities for group business. See Anderson et al. (2007) for more exhaustive examples and extensions to multiple prices.

Hotels are slowly moving to managing total property revenues versus simply room's revenues.

The other extreme is casino properties that often focus only on gambling revenues-managing the rooms in an effort to ensure the proper mix of casino guests are accepted. These extremes are starting to converge as casinos are beginning to focus on room revenue as well as gambling revenues-moving to an inclusion of retail and food beverage revenues as their mix of guests move away from being pure casino guests. Hotels are also starting to focus on other aspects of their revenue equation. In Chapter 37, Kimes and Singh provided an interesting illustration of a more concerted effort to pricing other hotel services, here spa revenues. Similar to a hotel's focus on revenue per available room (RevPAR) a spa may use revenue per available treatment hour (RevPATH) as a metric of performance. Kimes and Singh (in Chapter 37) focused on estimating RevPATH and then provide illustrative examples of methods to improve revenues. Similar to Kimes (in Chapter 34), they highlighted strategic pricing issues and the role of rate fences within a spa setting. Analogous to early RM approaches, they recommended a categorization of RevPATH performance into "hot" and "cold" periods; where in hot or high RevPATH periods spas need to focus on high yielding spa guests, in cold or low RevPATH periods, spas need to focus on increasing demand. As many full service and luxury properties also offer spa services, the coordination of spa demand with that of the property is only natural. The bundling and marketing of spa treatments with rooms during cold RevPATH and RevPAR periods is a simple way for firms to add incremental demand to both. As firms move to bundling their own services (to create incremental demand), they need to focus on the marketing of these efforts as nonmarketed bundling may also cause dilution from guests whom would have paid full price for both. Similar to the coordination of spa and rooms, revenue firms can more actively integrate the efforts at strategically pricing all ancillary services. This integration need not be complex but rather similar to Kimes and Singh's (see Chapter 37) isolation of revenue opportunities with the ancillary service (spa, golf, food and beverage [F \& B], facilities, etc.) followed by coordinated marketing of the bundle.

\section{Conclusion}

Pricing will continue to play increasing importance in RM-especially during periods of softer demand. Historically, RM systems have functioned largely on accepting higher yielding demand and rejecting discounted demand, but during weak periods of demand, all rate classes remain open and 
price setting becomes a key function of RM. Strategic pricing will take many forms as firms attempt to set revenue maximizing prices across segments, dynamically change these prices in response to competitor actions, and demand uncertainties. Firms need to ensure that only elastic market segments are presented with price decreases while maintaining prices for more brand loyal inelastic segments. As firms look to target price sensitive segments, they will focus more on total RM as they bundle ancillary services and more aggressively seek group demand in an effort to increase yields with brand loyal transient demand.

\section{References}

Anderson, C. K. (2009). Setting prices on Priceline. Interfaces, 39(4), 307-315.

Anderson, C. K., \& Carroll, W. J. (2007). Demand management: Beyond revenue management. Journal of Revenue Management and Pricing, 6(4), 260-263.

Anderson, C. K., Carroll, W. J., \& Li, M. Z. F. (2007). Room pricing, rate fences and group profitability. Ithaca, NY: Cornell University, School of Hotel Administration.

Anderson C. K., \& Xie, X. (2009). A choice based dynamic programming approach for setting opaque prices. Ithaca, NY: Cornell University, School of Hotel Administration.

Marriott, J. W., \& Cross, R. G. (2000). Room at the Revenue Inn. In Peter Krass (Ed.), The book of management wisdom: Classic writings by legendary managers (pp. 199-208). New York: Wiley.

Schwartz, Z., \& Cohen, E. (2003). Hotel revenue management with group discount room rates. Journal of Hospitality \& Tourism Research, 27(1), 24-47.

Smith, B. C, Leimkuhler, J. M., \& Darrow, R. M. (1992). Yield management at American Airlines. Interfaces, 22(1), 8-31. 